\title{
Alcohol and Placebo: The Role of Expectations and Social Influence
}

\section{Vivien Bodnár ${ }^{1} \cdot$ Krisztina Nagy $^{2}$ • Ádám Cziboly ${ }^{2}$. György Bárdos ${ }^{2}$}

Published online: 15 June 2020

(C) The Author(s) 2020

\begin{abstract}
The placebo effect is frequently present in our lives when an expectation, associated with any psychoactive material, leads to subjective and physiological changes. The present work studies the role of expectancies associated with ethanol/alcohol in changes to the subjective state. In experimental situations, we examine how these expectations - with or without social influences - affect participants when consuming alcoholic, pseudo-alcoholic, or non-alcoholic cocktails. Psychological and physical changes can, to a significant extent, arise from an expectation-driven placebo effect. We suggest that expectations of inebriation formed by socialization and experiences can explain most of the behavioural changes following alcohol consumption. These effects seem to be stronger if the alcohol consumption happens in a social context and weaker if it is individually. Regarding the information effect, we suppose that the expectations will positively affect the drunkenness, i.e. toward the placebo "direction": those who believe they are consuming a nonalcoholic cocktail will be less inebriated than those who know their drink contains alcohol. In this study, we successfully demonstrate the expectation-induced classical placebo effect in the misinformed participants who were, in fact, consuming nonalcoholic drinks. The "social" alcohol consumption further enhances the true or believed effects of the alcohol, and thus the participants reported their subjective feelings in lines with their manipulated expectations. As regards the effect of the alcohol, therefore, many other factors contribute in addition to the alcohol itself, the most important of which seem to be group effect, suggestions and expectations.
\end{abstract}

Keywords Placebo $\cdot$ Alcohol $\cdot$ Expectations $\cdot$ Social drinking $\cdot$ Factor analysis

György Bárdos

bardos.gyorgy@ppk.elte.hu

1 Doctoral School of Psychology, Institute of Psychology, ELTE Eötvös Loránd University, Budapest, Hungary

2 Institute of Health Promotion and Sport Sciences, Budapest, Faculty of Education and Psychology, ELTE Eötvös Loránd University, Bogdánfy Ödön u. 10/B, Budapest 1117, Hungary 
In everyday life, we know several phenomena in which the effect of a substance cannot be explained solely by its chemical properties. When taking medication, the analgesic effect usually occurs earlier than the drug absorption and metabolism can explain; simply getting to the family doctor can bring relief and reduce our symptoms; decaffeinated coffee may help us stay awake, and we can become tipsy after consuming an alcohol-free drink. In these cases, another significant factor plays an important role, beyond the biochemical effects of the active substance, namely the so-called placebo effect. On the other hand, the effect of a chemical agent, such as alcohol, can be modified by our thoughts and beliefs in the "opposite direction", i.e. drunk (until a certain level of intoxication) people can become sober if the situation requires it. Thus, expectations and beliefs partly determine how we respond to certain substances (Bombeke 2012; Knibb et al. 2018). Expectations associated with alcohol consumption, acquired through socialization and experiences, can therefore be more active in a social environment than in the case of solitary drinking (Kirkpatrick and Wit 2013).

The most often cited definition of placebo is that by Shapiro and Shapiro (1997): "A placebo is any therapy (or component of any therapy) that is intentionally or knowingly used for its nonspecific psychological, or psychophysiological therapeutic effect, or it is used for a presumed specific therapeutic effect on a patient, symptom, or illness but without specific activity for the condition being treated." An alternative to this medically determined definition was created by Ross and Olson (1981): "A placebo is a substance or procedure that is administered with suggestions that it will modify a symptom or sensation but which, unknown to its recipient, has no specific pharmacological impact on the reaction in question." This implies that the effect of any substance consumed is not dependent solely on its pharmacological properties. Brody (2000) expands the definition by stating that "the placebo response is a somatic (or psychosomatic) change which is elicited by the symbolic meaning attributed to a person or object of a curative environment".

The mechanism of the placebo effect can be conditioning and/or expectations. Conditioning is regarded predominantly as physiological, whereas expectations are more complex, humanspecific features requiring consciousness and are rather psychological in character (Crow et al. 1999; Dömötör et al. 2015; Harrell and Juliano 2009; Szemerszky et al. 2013). The former can be extinguished when proper reinforcement is missing, whereas the latter can be eliminated by diminishing anticipation.

The everyday placebo effect can be demonstrated with several substances, including caffeine, nicotine or alcohol (Bérdi et al. 2015; Szabo et al. 2017; de la Vega et al. 2017). In the case of alcohol, it is difficult to find a good placebo (Lachenmeier et al. 2016; Schlauch et al. 2010) because participants are familiar with the taste and the effect of the substance. Considering the pharmacological effect of ethanol, alcohol is a general suppressant and antidepressant, mainly affecting information processing, memory, body sensations and motor performance (Bombeke 2012; Gilbertson et al. 2010; Rodríguez Rodríguez et al. 2016). In the case of excessive consumption, symptoms of alcohol intoxication can be detected, mediated by the effect of ethanol on brain cells. Pharmacological effects and the impact of expectancies are dose-dependent; in the case of small quantities, expectancies have a greater role than in the case of large doses, where the chemical effect of the substance might dominate (AlfonsoLoeches and Guerri 2011; Brust 2010; Cederbaum 2012; Guerri and Pascual 2010; Moonat et al. 2010; Zahr et al. 2011). These two effects are influenced by individual differences: body composition, drinking habits, gender and genetic heritage modulate the pharmacological mechanism (Morean and Corbin 2010), whereas individual expectations, experiences, beliefs and attitudes have an impact on the expectation mechanism (Bowdring and Sayette 2018, Dömötör et al. 2015, Szemerszky et al. 2013). 
Beyond the pharmacological effects, alcohol-related expectations have to be taken into consideration, which are essentially formed from personal experiences and particular cultural values (Marlatt and Rosenhow 1980; Price and Finniss 2008; Thompson 2000). Christiansen et al. (1982) identified six factors of alcohol-related expectancy: 1) alcohol as a global, positive transforming agent, 2) enhancing sexual performance, 3) enhancing social and physical pleasure, 4) increasing social assertiveness, 5) providing relaxation/tension reduction, and 6) increasing power and aggression. Of these six factors, five are already observable among the young - as yet non-consuming - population. Some of the expectations are acquired through socialization; others are formed through drinking experience (Guerri and Pascual 2010). Their consistency and homogeneity grow through individual experiences.

The awareness of drinking alcohol and the consumption itself are inseparable in everyday life. However, to investigate the placebo mechanism, it is necessary to separate pharmacological effects from expectancies (Bárdos 2011).

Some authors (e.g. Abrams et al. 2001; Crow et al. 1999; Marlatt and Rosenhow 1981) have separated the impact of expectation and ethanol, and found that the expectation, especially in the case of social drinking, has a significant impact on social behaviour, for example in stimulating antisocial behaviour, while the ethanol itself affects the cognitive and physiological processes, causing inaccuracies in perception and motor functions, increasing sexual arousal, inhibiting memory processes and improving mood. Ethanol was also found to enhance gastrointestinal detection, trigger hot flashes and improve dynamic peripheral perception (Abroms et al. 2003; Bjork and Gilman 2014; Connors and Maisto 1979; Gardner and Mouton 2015; Gorka et al. 2018; Stevens et al. 2014; Vuchinich et al. 1979; Weafer et al. 2016).

Studies focusing on expectancies, using an appropriate placebo, have found that reactions similar to those caused by the original agent, i.e. alcohol, were triggered, such as impaired performance and subjective intoxication symptoms (Bárdos 2011; Bodnár et al. 2018, Bombeke 2012, Nagy et al. 2007, Price and Finniss 2008, Rodríguez et al., 2016, Schlauch et al. 2010).

It seems inherent in these types of studies that participants' perceptions are shaped in accordance with the given instructions: those who drink alcohol and are aware of it become tipsier than those who have false information and think they are consuming an alcohol-free beverage. Similarly, those who drink the placebo and think they are consuming alcohol become tipsier than those who have accurate information (Bárdos 2011; Bombeke 2012; Christiansen et al. 2017; Knibb et al. 2018).

Although many researchers have assumed that pharmacological and expectancy-related interactions can be brushed aside, a modern magnetic resonance imaging (MRI) test showed that the consumption of alcohol and the awareness of drinking have opposite effects on the prefrontal cortex and cingulum, and thus the above-mentioned interaction seems to exist (Bjork and Gilman 2014; Gundersen et al. 2008).

Other studies have found controversial results, probably explained by the so-called reverse or compensatory placebo response concept. Fillmore et al. (1994) gave placebo alcohol and placebo caffeine to participants, accompanied by stimulating or inhibiting information about the expected drug effect on a pursuit rotor task and performance. In the caffeine setting, participants' performance was in accordance with the instruction, whereas in the alcohol setting the effect was reversed: performance deteriorated in the group receiving alcohol placebo with stimulating information, whereas with inhibiting information the psychomotor performance improved. 
The motivation of the participants may lie in the background of this seemingly paradoxical phenomenon: those who felt a disadvantage because of the inhibition by the consumed "alcohol" made a greater effort to compensate. It seems, therefore, that one can overcome the effect of alcohol to a certain extent, that is, in addition to the physiological processes, psychological effects may also determine the outcome after the consumption of alcohol or placebo-alcohol. This compensatory effect may be enhanced by conditioning, and can be generalized to other situations and can be extinguished by omitting the reward. This type of compensatory behaviour may be observed when consuming either alcohol or placebo, respectively (Fillmore and Vogel-Sprott 1996). In everyday life, this phenomenon can be observed when certain situations require soberness, and the inebriated minds suddenly become clear. In addition, the effect can be significantly modified by the motivation for drinking alcohol (Bailey and Baillie 2013, Christiansen al., 2017).

In the present study, in addition to testing the placebo expectations straightforwardly by telling the subjects they were consuming alcohol but serving placebo, the reverse condition was tested, i.e. telling them they were consuming aroma (placebo) but serving alcohol. This latter condition has been less commonly studied and can improve our insight into the alcohol-placebo relationship.

The study also examined the placebo effect both in individual and in group settings. We supposed that group processes would have a significant effect on the results, since the everyday consumption of alcohol takes place mainly in social situations, and thus alcoholrelated expectations may differ. These facts largely determined the study hypotheses.

\section{Hypotheses}

We assumed that ethanol is only partially responsible for the feeling of inebriation; therefore, expectations connected to socialization and experience (Abrams et al. 2001; Crow et al. 1999; Fillmore and Vogel-Sprott 1996; Marlatt and Rosenhow 1980) can explain a significant part of the subjects' mental and physical temporary state change following consumption.

\section{Hypothesis 1}

Compared to participants who had consumed real alcohol, subjects drinking alcohol-free placebo cocktails will demonstrate similar changes in mental and physical temporary states because they will believe they are drinking alcohol. This hypothesis predicts that in the case of a small amount of alcohol consumption, the expectancy itself can generate mental and physical temporary state changes as though it were real alcohol consumption.

\section{Hypothesis 2}

We assumed that group processes would have a significant effect on the results, since everyday consumption of alcohol takes place mainly in social situations, and thus alcohol-related expectations may differ. Therefore, compared to individuals who are drinking alone, participants drinking in a social environment will feel tipsier, as demonstrated by a higher score on the visual analogue scale.

\section{Hypothesis 3}

Because of the information effect, we also assumed that the effects of alcohol could be modified by individuals' thoughts and beliefs in the "opposite direction"; i.e. drunk (until a 
certain level of intoxication) people can become sober if it is necessary in a given situation. Thus, expectations and beliefs partially determine how we respond to certain substances.

Therefore, in the social setting, participants drinking real alcohol but believing they are in the "alcohol-free setting" will demonstrate a lower score on the visual analogue scale as compared to subjects who are aware of drinking real alcohol.

\section{Materials and Methods}

\section{Participants}

Participants were recruited through a specific Facebook call, and 800 flyers were also distributed at the largest universities in Budapest. The advertisement contained a brief description of the study, which was a deceptive story stating: "A research testing physical changes related to alcohol consumption", and pointed to a link to the online questionnaire. The questionnaire contained demographic questions including age, gender and education level, and questions regarding drinking habits and attitudes toward alcohol consumption. Students who completed the questionnaire, were at least 18 years of age, and had not reported any symptoms of alcohol abuse or heavy drinking were included in the study and randomly assigned to different settings and experimental groups. Subjects under the legal drinking age, those suffering from alcoholism or reporting regular alcohol consumption, or who were allergic to any ingredient used in the experiment were excluded from the study. The study included 136 participants, 88 men (63.3\%) and 51 women (36.7\%) living in Budapest, whose mean age was 22.8 years $(N=136, \mathrm{SD}=2.79$, min. $=18$, max. $=26)$. The research was carried out in eight sessions in a classroom at ELTE University in the evening hours after lectures, with two different conditions, i.e. individual (3-6 participants/occasion) and social (18 participants/occasion), under three different settings.

\section{Procedure}

The use of placebos in experiments on the consumption and effects of alcohol is problematic, because people are very familiar with the taste of alcohol. It is also difficult to present placebo versus alcohol in a discreet way (Hrobjartsson and Gøtzsche 2004; Lachenmeier et al. 2016; Mendelson et al. 1984; Schlauch et al. 2010).

In our experiment, we used a common rum drink (alcohol + aroma) or, for placebo, the same rum aroma available in department stores. Four centiliters of rum or aroma was mixed with 16 cL Coke. In a conference of physiologists, 15-15 cocktails were offered to participants arriving at random, who were asked to judge whether they had consumed alcohol or aroma in the cocktail. Participants responded randomly, and fewer than half were correct.

To examine the problems raised and to test the three hypotheses, different settings were used, which differed in whether the participants consumed alcohol (rum, A) or placebo (aroma, P), whether or not they had been correctly informed, and whether they took part individually or in groups (I vs. S). The conditions are shown in Table 1. If the first (informed about what they would drink, A or P) and the second (what was really consumed) letters are the same, the participant was correctly informed. If the two letters are different (e.g. AP-I), the participant was misinformed (i.e. were told they would be drinking rum but received aroma). 
Table 1 The three study conditions. A: alcohol (rum), P: placebo (aroma), I: individual, S: social

\begin{tabular}{|c|c|c|c|c|c|}
\hline & Given information & $\begin{array}{l}\text { Number of } \\
\text { participants }\end{array}$ & $\begin{array}{l}\text { Consumed } \\
\text { cocktail }\end{array}$ & Condition & Notation \\
\hline \multirow{4}{*}{$\begin{array}{l}\text { 1. Setting } \\
1 \\
\text { 2. Setting }\end{array}$} & \multirow{2}{*}{$\begin{array}{l}\text { Believed to be drinking } \\
\text { alcohol }\end{array}$} & 21 & Alcohol (A) & \multirow{2}{*}{$\begin{array}{l}\text { Individual } \\
\text { (I) }\end{array}$} & AA-I \\
\hline & & 16 & Placebo $(\mathrm{P})$ & & \multirow{3}{*}{$\begin{array}{l}\text { AP-I } \\
\text { PA-S } \\
\text { AA-S }\end{array}$} \\
\hline & \multirow{2}{*}{$\begin{array}{l}\text { Believed to be drinking aroma } \\
\text { Believed to be drinking } \\
\text { alcohol }\end{array}$} & 15 & Alcohol (A) & \multirow{2}{*}{$\begin{array}{l}\text { Social (S) } \\
\text { Social (S) }\end{array}$} & \\
\hline & & 3 & Alcohol (A) & & \\
\hline \multirow{2}{*}{$\begin{array}{l}\text { 3. Setting } \\
1\end{array}$} & \multirow{2}{*}{$\begin{array}{l}\text { Believed to be drinking } \\
\text { alcohol }\end{array}$} & 42 & Alcohol (A) & \multirow[t]{2}{*}{ Social (S) } & AA-S \\
\hline & & 39 & Placebo $(\mathrm{P})$ & & AP-S \\
\hline
\end{tabular}

In the first, so-called individual setting, participants took part in the experiment individually, and all were informed that they were drinking alcohol. Among these participants, $56.8 \%$ $(n=37 ; 19$ men and 18 women; mean age: 23.1 years; $\mathrm{SD}=4.13$ years) received $4 \times 4 \mathrm{cL}$, $37.5 \%$ real rum mixed with $16 \mathrm{cL}$ Coke (AA-I), whereas the remainder $(43.2 \%)$ drank an alcohol-free cocktail containing $4 \mathrm{cL}$ rum aroma and $16 \mathrm{cL}$ Coke, with the same colour, flavour and texture of a real rum \& Coke (AP-I).

In the second, so-called social setting, 18 participants ( 8 men and 10 women; average age: 22.5 years; $\mathrm{SD}=1.42$ years) attended, sitting close to each other, favouring social influence. In this condition, each participant received the same $4 \times 4 \mathrm{cL}, 37.5 \%$ real rum \& Coke mix as earlier (A). Some of the group were told that they would be drinking real alcohol (AA-S), whereas others were told they would only drink non-alcoholic rum-flavoured cocktails (PA-S).

Table 2 Results of the testing of the alcohol levels

\begin{tabular}{|c|c|c|c|}
\hline $\begin{array}{l}\text { Breath level }(\mathrm{mg} / \mathrm{L} \\
\text { Standards }\end{array}$ & \multicolumn{2}{|l|}{ Blood level (g/L) } & Interpretation \\
\hline$<0.1 \mathrm{mg} / \mathrm{L}$ & \multicolumn{2}{|l|}{$<0.2 \mathrm{~g} / \mathrm{L}$} & No ingestion detected \\
\hline $0.11-0.25 \mathrm{mg} / \mathrm{L}$ & \multicolumn{2}{|l|}{$0.21-0.5 \mathrm{~g} / \mathrm{L}$} & Ingested but no effect \\
\hline $0.26-0.4 \mathrm{mg} / \mathrm{L}$ & \multicolumn{2}{|l|}{$0.51-0.8 \mathrm{~g} / \mathrm{L}$} & Very mild effect \\
\hline $0.41-0.75 \mathrm{mg} / \mathrm{L}$ & \multicolumn{2}{|l|}{$0.81-1.5 \mathrm{~g} / \mathrm{L}$} & Mild effect \\
\hline $0.76-1.25 \mathrm{mg} / \mathrm{L}$ & \multicolumn{2}{|l|}{$1.51-2.5 \mathrm{~g} / \mathrm{L}$} & Moderate effect \\
\hline $1.26-1.75 \mathrm{mg} / \mathrm{L}$ & \multicolumn{2}{|l|}{$2.51-3.5 \mathrm{~g} / \mathrm{L}$} & Serious effect \\
\hline$>1.76 \mathrm{mg} / \mathrm{L}$ & \multicolumn{2}{|l|}{$>3.51 \mathrm{~g} / \mathrm{L}$} & Very serious, deep effect \\
\hline \multicolumn{4}{|l|}{ Data } \\
\hline \multicolumn{4}{|l|}{ Alcohol group } \\
\hline Probe & Breath level (mg/L) & Blood alcohol (g/L) & Interpretation \\
\hline 0 & 0 & 0 & No ingestion detected \\
\hline 1 & $0.25 \pm 0.03$ & 0.256 & Ingested but no effect \\
\hline 2 & $0.4 \pm 0.03$ & 0.472 & Ingested but no effect \\
\hline 3 & $0.8 \pm 0,07$ & 0.688 & Very mild effect \\
\hline 4 & $1.6 \pm 0.15$ & 0.904 & Mild effect \\
\hline \multirow[t]{2}{*}{5} & $1.9 \pm 0.22$ & 1.12 & Mild effect \\
\hline & Placebo group & & \\
\hline Probe & Breath level (mg/L) & Blood alcohol (g/L) & \\
\hline 0 & 0 & 0 & No ingestion detected \\
\hline 1 & 0 & 0 & No ingestion detected \\
\hline 2 & 0.1 & 0 & No ingestion detected \\
\hline 3 & 0 & 0 & No ingestion detected \\
\hline 4 & 0 & 0 & No ingestion detected \\
\hline 5 & 0.1 & 0 & No ingestion detected \\
\hline
\end{tabular}


Table 3 The number of participants reporting to be more inebriated after the experiment

\begin{tabular}{|c|c|c|c|c|c|c|}
\hline & & \multicolumn{4}{|c|}{ Condition } & \multirow[t]{2}{*}{ Total } \\
\hline & & $\begin{array}{l}\text { AA- } \\
\text { I }\end{array}$ & $\begin{array}{l}\text { AP- } \\
\text { I }\end{array}$ & $\begin{array}{l}\text { PA- } \\
\text { S }\end{array}$ & $\begin{array}{l}\text { AA- } \\
\mathrm{S}\end{array}$ & \\
\hline \multirow[t]{2}{*}{ Do you feel more inebriated than you were at the time of your arrival? } & Yes & 21 & 16 & 12 & 3 & 52 \\
\hline & No & 0 & 0 & 3 & 0 & 3 \\
\hline Total & & 21 & 16 & 15 & 3 & 55 \\
\hline
\end{tabular}

Fifteen people were told that they were in the "alcohol-free setting", thus believing they were drinking alcohol-free cocktails (PA-S), whereas three participants were given the correct information regarding the ingredients of the cocktail in order to maintain and strengthen the cover story (AA-S).

In the third setting ( $n=81 ; 61$ men and 23 women; average age: 22.8 years; $\mathrm{SD}=2.8$ years), participants were told that they would be drinking alcohol. Half of the subjects $(51.9 \%)$ consumed $4 \times 4 \mathrm{cL}, 37.5 \%$ real rum and $16 \mathrm{cL}$ Coke mix (AA-S), whereas the other half $(48.1 \%)$ consumed the same amount of non-alcoholic cocktails with rum flavour (AP-S). The structure of the setting was more or less the same as the first setting, but in this case, the test took place in a social environment, with 10 to 20 people taking part in the experiment at the same time.

In order to observe the dynamics of the different settings, each participant was asked to consume four cocktails (16 cL Coke $+4 \mathrm{cL}$ rum or aroma) separated by 15 -min intervals. Participants were tested before the first cocktail (baseline) and immediately after each of the four cocktails (see below).

\section{Testing}

Prior to the research sessions, we tested alcohol levels at the different stages of the experimental situation using a common alcohol detector (Dimarson alcohol test kit). Table 2 shows the results of the testing.

In order to examine whether the deception was successful, at the end of the experiment we asked the participants if they felt more inebriated than they had been at the time of their arrival. Responses given by the participants are summarized in Table 3:

Table 4 MLFA with varimax rotation: the eigenvalues and cumulative variance of the two factors in the five tests

\begin{tabular}{llll}
\hline Test & Factors & Eigenvalue & Cumulative variance \\
\hline 1 & 1 & 4646 & $27.328 \%$ \\
& 2 & 2940 & $44.621 \%$ \\
2 & 1 & 6021 & $35.417 \%$ \\
& 2 & 3505 & $56.033 \%$ \\
3 & 1 & 6486 & $38.152 \%$ \\
4 & 2 & 3392 & $58.103 \%$ \\
& 1 & 5892 & $34.657 \%$ \\
5 & 2 & 3963 & $57.971 \%$ \\
& 1 & 5898 & $34.695 \%$ \\
\hline
\end{tabular}


Table 5 The rotated component matrix based on the fifth test with 15 variables (extraction method: MLFA; rotation method: varimax; rotation converged in 3 iterations)

\begin{tabular}{lll}
\hline & \multirow{2}{*}{ Rotated Factors } & \\
\cline { 2 - 2 } & First factor & Second factor \\
\hline Passive-active & .864 & \\
Withdrawn-sociable & .846 & \\
Silent-talkative & .824 & \\
Sad-cheerful & .819 & \\
Shy-relieved & .805 & \\
Timid-brave & .795 & .865 \\
Hesitant-self-confident & .693 & .811 \\
Subordinate-dominant & .660 & .809 \\
Apathetic-interested & .647 & .762 \\
Sharp-minded-dull-minded & & .776 \\
Alert-confused & & .647 \\
Rational-irrational & & \\
Fully sober-completely drunk & & \\
Prudent-impulsive & & \\
Calm stomach-upset stomach & & \\
\hline
\end{tabular}

At five points during the experiment - before the first cocktail (baseline) and immediately after each cocktail — we assessed the subjective judgement of the subjects' mental and physical temporary state by a visual analogue scale consisting of 17 pairs of statements (shy-relieved, withdrawn-sociable, sad-cheerful, sleepy-vigilant, sharp-minded-dull-minded, alert-confused, passive-active, subordinate-dominant, silent-talkative, fully sober-completely drunk, calm stomach-upset stomach, apathetic-interested, timid-brave, feel good-feel bad, rationalirrational, prudent-impulsive, hesitant-self-confident). The visual analogue scale was then converted into a hundred graded Likert scale Tables 4 and 5.

All experimental settings were approved with the strict oversight of the Ethics Committee of the Faculty of Education and Psychology, Eötvös Loránd University.

\section{Data Processing}

All statistical analyses were carried out using SPSS 14.0 statistical software (SPSS, Inc., Chicago, IL, USA).

\section{Results}

Repeated-measures ANOVAs were conducted to determine whether mean ratings for the social and subjective feelings factors differed as a function of:

Hypothesis 1: the type of cocktail (alcohol/aroma)

Hypothesis 2: the social setting (individual/social)

Hypothesis 3: the given information (aware of drinking alcohol/ believed to be drinking placebo). 
Test order was entered as the within-subject factor, and the condition (alcohol/aroma, individual/social, aware/knowledge of placebo) was entered as the between-subject factor.

As the first step, the visual analogue scale of 17 pairs of characteristics was examined by using exploratory factor analysis with the maximum likelihood method (MLFA) and varimax rotation in each of the five consecutive tests. To ensure suitability for conducting factor analysis, this study used the Kaiser-Mayer-Olkin (KMO) test and Bartlett's test of sphericity. The result of the KMO test was acceptable (over 0.6) in all measures, and Bartlett's test of sphericity was significant $(p<0.001)$ in all cases. Both tests indicated the suitability of the variables for factor analysis.

MLFA with varimax rotation consistently yielded two factors (factors 1 and 2) in all five measurements. In addition, based on the scree plot and on the eigenvalues and cumulative variance, two additional, secondary factors appeared beyond the two primary factors. When taking these into account, however, the cumulative variance did not change significantly.

The first factor of the overall four-factor structure based on the fifth measurement, called the "social factor" (5.251, MMV $=30.889 \%)$, contained the following variables: passive-active, withdrawn-sociable, silent-talkative, sad-cheerful, shy-relieved, timid-brave, hesitant-selfconfident, subordinate-dominant, apathetic-interested. The second factor, called the "subjective feelings factor" (2769, MMV=47,176\%), contained the sharp-minded-dull minded, alert-confused, rational-irrational, fully sober-completely drunk, prudent-impulsive, calm stomach-upset stomach variables.

In the four-factor structure, the rational-irrational and reflective-impulsive variables defined a third factor $(1.427, \mathrm{MMV}=55.672 \%)$, which on the basis of its variables is called the "impulsivity factor". The fourth factor $(1.143, \mathrm{MMV}=62.297 \%)$, called the "general feeling factor", contains only the feel good-feel bad variable. Since the sleepy-vigilant variable is weighted on more factors, and the feel good-feel bad variable defined a "secondary factor" on its own, these were omitted from further analysis. The results clearly confirm the two-factor structure, wherein the eigenvalue of the first factor is 5.561 (MMV=37.075\%), and of the second is $3.624(\mathrm{MMV}=61.238 \%)$.

In order to control for the initial "pseudo" differences between the groups, for each analysis we used a "corrected" setting, extracting the results of the first test from tests $\mathrm{N}^{0} 2-5$.

The first hypothesis, predicting that participants consuming real alcohol and subjects drinking alcohol-free placebo cocktails would demonstrate similar mental and physical temporary state changes, was supported, since there was no significant difference regarding social behaviour and subjective feelings in either individual or group settings between those consuming alcohol and those consuming aroma who were unaware that they had received placebo.

The second hypothesis, predicting that drinking in a social environment would result in higher scores on the visual analogue scale, was not supported in either the alcohol or the aroma group, since no significant differences were obtained.

The third hypothesis, predicting that, in a social environment, the awareness of drinking real alcohol would be associated with more symptoms of inebriation, and participants drinking real alcohol but believing that they were in the "alcohol-free setting" would demonstrate a lower score on the visual analogue scale, was also not supported, again with no significant differences between groups.

Although the five groups showed different patterns in social and subjective feelings factors (Figs. 1 and 2, respectively), the results of the repeated-measures ANOVA showed no significant main effect of time or interaction effect or a difference between groups in any case 
of the two factors. With reference to Figs. 1 and 2, however, it is clear that the results of the PA-S and AP-S conditions differ from the other conditions. Participants in PA-S (believed to drink aroma/consumed alcohol/social), who had collectively consumed alcohol while believing they were drinking only aroma, showed a decline in the social factor along the five tests, becoming less and less "social", initiator, talkative, etc. This can be explained, on one hand, by the fact that the manipulation of information suggesting that participants would not be drinking alcohol "discouraged them", and thus they compensated their behaviour based on the given information and became less "social", as "there was no reason to become more social". AP-S (believed to drink alcohol/consumed aroma/social), who had collectively consumed rum flavour believing they drank alcohol, achieved a higher value on the social factor than other groups, as they were more social. This seems to be a reverse compensation effect as compared to the condition where participants believed they would not be consuming alcohol (although in fact they did) Fig. 3.

The other three groups showed roughly the same pattern through the third test, but during the last two tests, AA-S (believed to consume alcohol/consumed alcohol/social) showed an increasing trend, whereas AA-I (believed to drink alcohol/consumed alcohol/individual) showed a decreasing trend. The results for the individual aroma consumers (AP-I: believed to drink alcohol/consumed aroma/individual) were unchanged throughout the tests.

In the social settings, those who believed they were drinking alcohol reported increasing subjective symptoms (dull consciousness, confusion, being heavily drunk, upset stomach, impulsive and irrational). Interestingly, the real alcohol consumers among them (AA-S: believed to drink alcohol/social/consumed alcohol) reported fewer symptoms than the aroma consumers (AP-S: believed to drink alcohol/social/consumed aroma), who showed a marked increase after the third and fifth tests, which can be considered a compensation/placebo effect. Participants in social conditions, regardless of what they were really drinking, reported increasing symptoms associated with inebriation, while individual participants had no significant change in this respect during the tests. Neither the consumed quantity of the given ethanol nor the short interval of time in the experiment could have justified the presence of

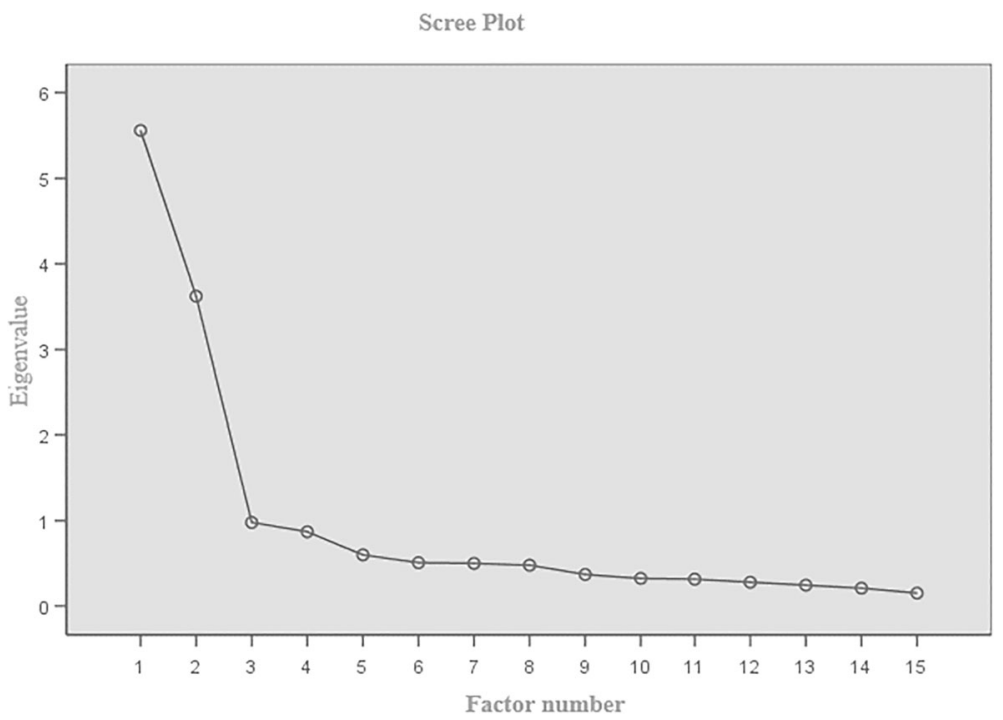

Fig. 1 Scree plot of the fifth test 


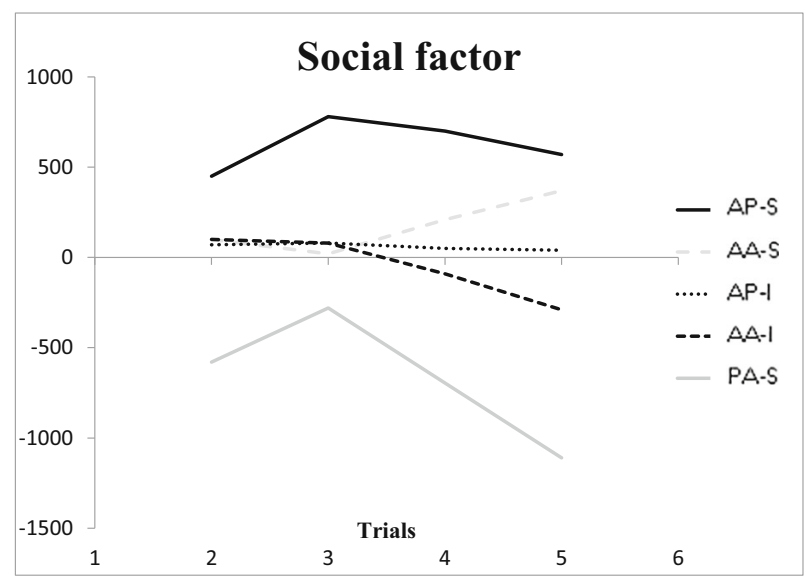

Fig. 2 Distribution of group means of the five groups along the social factor

subjective symptoms of inebriation. Therefore, the group effect is a stronger predictor of the outcomes than the ethanol itself.

\section{Discussion}

The present study examined the mechanisms of the placebo effect in relation to alcohol consumption, specifically the effect of aroma or alcohol consumption on self-evaluation of the subjective physical, emotional and social state, in both group and individual settings.

A classical placebo effect was demonstrated in the present study: there was no significant difference regarding social behaviour or subjective feelings between alcohol- and aromaconsuming subjects when they did not know that placebo had also been served, in either the individual or group setting. It seems that it is enough for people to believe they have consumed alcohol to feel inebriated.

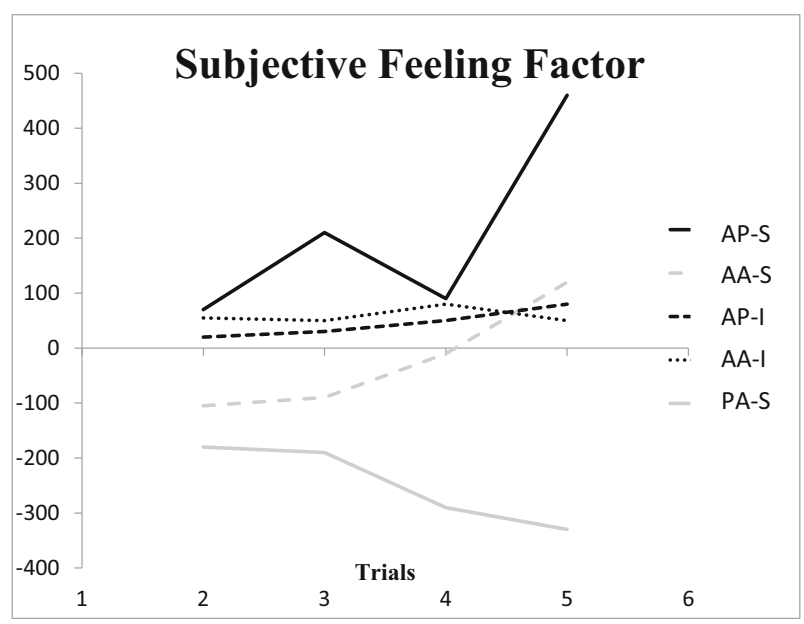

Fig. 3 Distribution of group means of the five groups along the subjective feelings factor 
The aim of the study was also to clarify the role of group conditions in the placebo effect. Comparing the results of the individual and group settings, regardless of the alcohol content of the consumed cocktail, a social atmosphere intensified the effects of alcohol consumption.

A significant compensation effect was observed with the manipulation of the instructions (believed to drink alcohol/aroma), which was further enhanced by group effects. Because of the consumed amount of ethanol or aroma, theoretically subjects should not have reported feelings of inebriation, but due to strong stereotypes associated with alcohol consumption, regardless of the alcohol content, they "created" physical symptoms when they believed they were drinking alcohol. On the other hand, those who believed they were drinking only aroma, despite the fact that a real rum cocktail was given to them, showed signs of compensation as well, and they claimed to be "more sober" in order to harmonize their beliefs and feelings. We conclude that up to a certain amount of ethanol, subjective feelings of drunkenness are mainly defined by expectations, and expectation-related stereotypes are more powerful in a social than in an individual context.

To summarize, the effect of alcohol can only be partly explained by ethanol, as several other factors - mainly social processes, suggestions and expectations - play an important role in how individuals become inebriated.

\section{Limitations}

This study presents the various effects of aroma and alcohol consumption on the basis of selfevaluation of the subjective physical, emotional and social state in group and individual settings in a healthy and young population with no alcohol-related disease or intolerance. Stereotypes, expectations, attitudes and experiences related to alcohol consumption of the tested sample may also differ from those of other populations, precluding wide generalizability of the results.

The relevant tests indicated the suitability of the variables for factor analysis and repeatedmeasures ANOVA, although the sample size was relatively small, which can also limit broad interpretation.

Finally, due to the small amount of alcohol consumed and the relatively short time intervals, participants only experienced a mild effect, whereas in real-life situations, people usually consume larger amounts and spend more time under those conditions. Although this fact seems to limit the validity of our study, it could still be a good design choice, since in a stronger inebriated state the placebo probably would not work.

Funding Information Open access funding provided by Eötvös Loránd University (ELTE).

\section{Compliance with Ethical Standards}

Conflict of Interest The authors V. Bodnár, K. Nagy, Á. Cziboly and G. Bárdos declare that they have no conflict of interest.

Informed Consent All procedures followed were in accordance with the ethical standards of the responsible committee on human experimentation (institutional and national) and with the Helsinki Declaration of 1975, as revised in 2000. Informed consent was obtained from all patients for being included in the study.

Additional informed consent was obtained from all patients for which identifying information is included in this article. 
Open Access This article is licensed under a Creative Commons Attribution 4.0 International License, which permits use, sharing, adaptation, distribution and reproduction in any medium or format, as long as you give appropriate credit to the original author(s) and the source, provide a link to the Creative Commons licence, and indicate if changes were made. The images or other third party material in this article are included in the article's Creative Commons licence, unless indicated otherwise in a credit line to the material. If material is not included in the article's Creative Commons licence and your intended use is not permitted by statutory regulation or exceeds the permitted use, you will need to obtain permission directly from the copyright holder. To view a copy of this licence, visit http://creativecommons.org/licenses/by/4.0/.

\section{References}

Abrams, K., Kushner, M., Medina, K. L., \& Voight, A. (2001). The pharmacologic and expectancy effects of alcohol on social anxiety in individuals with social phobia. Drug and Alcohol Dependence, 64(2), 219-231.

Abroms, B. D., Fillmor, M. T., \& Marczinski, C. A. (2003). Alcohol-induced impairment of behavioral control: Effects on the alteration and suppression of prepotent responses. Journal of Studies on Alcohol, 64(5), 687-695.

Alfonso-Loeches, S., \& Guerri, C. (2011). Molecular and behavioral aspects of the actions of alcohol on the adult and developing brain. Critical Reviews in Clinical Laboratory Sciences, 48(1), 19-47.

Bailey, R. C., \& Baillie, A. J. (2013). The relationship between placebo alcohol and affect: Motives for drinking. Drug and Alcohol Reviews, 32(2), 162-169.

Bárdos, G. (2011). Mind the mind: The placebo and Nocebo phenomena. In E. Ribes \& J. Burgos (Eds.), Consciousness, perception, and behaviour: Conceptual, theoretical, and methodological issues (pp. 11-28). New Orleans, LA, USA: University Press of the South.

Bérdi, M., Köteles, F., Hevesi, K., Bárdos, G., \& Szabo, A. (2015). Elite athletes' attitudes toward the use of placebo-induced performance enchancement in sports. European Journal of Sport Science, 15(4), 315-321.

Bjork, J. M., \& Gilman, J. M. (2014). The effects of acute alcohol administration on the human brain: Insights from neuroimaging. Neuropharmacology, 84, 101-110.

Bodnár, V., Nagy, K., Ciboly, Á. C., \& Bárdos, G. (2018). The placebo effect and the alcohol. Journal of Mental Health and Psychosomatics, 19(1), 1-12.

Bowdring, M. A., \& Sayette, M. A. (2018). Perception of physical attractiveness when consuming and not consuming alcohol: A meta-analysis. Addiction, 113(9), 1585-1597.

Bombeke, K. (2012). The influence of alcohol and placebo effects on cognitive control. Master thesis in Experimental and Theoretical Psychology, Ghent University.

Brody, H. (2000). The placebo response. New York: Harper Collins.

Brust, C. T. M. (2010). Ethanol and cognition: Indirect effects, neurotoxicity and Neuroprotection: A review. International Journal of Environmental Research and Public Health, 7(4), 1540-1557.

Cederbaum, A. I. (2012). Alcohol metabolism. Clinics in Liver Disease, 16(4), 667-685.

Christiansen, B. A., Goldman, M. S., \& Inn, A. (1982). Development of alcohol-related expectancies in adolescents: Separating pharmacological from social-learning influences. Journal of Consulting and Clinical Psychology, 50(3), 336-344.

Christiansen, P., Townsend, G., Knibb, G., \& Field, M. (2017). Bibi ergo sum: The effects of a placebo and contextual alcohol cues on motivation to drink alcohol. Psychopharmacology, 234, 827-835.

Connors, G. J., \& Maisto, S. A. (1979). Effects of alcohol, instructions, and consumption rate on affect and physiological sensations. Psychopharmacology, 62(3), 261-266.

Crow, R., Gage, H., Hampson, S., Hart, J., Kimber, A., \& Thomas, H. (1999). The role of expectancies in the placebo effect and their use in the delivery of health care: A systematic review. Health Technology Assessment Review, 3(3), 1-93.

de la Vega, R., Alberti, S., Ruíz-Barquín, R., Soós, I., \& Szabo, A. (2017). Induced beliefs about a fictive energy drink influences 200-m sprint performance. European Journal of Sport Sciences, 17(8), 1084-1089.

Dömötör, Z., Szemerszky, R., \& Köteles, F. (2015). Subjective and objective effects of coffee consumption caffeine or expectations? Acta Physiologica Hungarica, 102(1), 77-85.

Fillmore, M. T., Mulvihill, L. E., \& Vogel, S. M. (1994). The expected drug and its expected effect interact to determine placebo responses to alcohol and caffeine. Psychopharmacology, 115(3), 383-388.

Fillmore, M. T., \& Vogel-Sprott, M. (1996). Evidence that expectancies mediate behavioral impairment under alcohol. Journal of Studies on Alcohol and Drugs, 57(6), 598-603.

Gardner, J. D., \& Mouton, A. J. (2015). Alcohol effects on cardiac function. Comprehensive Physiology, 5, 791-802.

Gilbertson, R., Prather, R., \& Nixon, S. J. (2010). Acute alcohol administration and placebo effectiveness in older moderate drinkers: Influences on cognitive performance. Journal of Studies in Alcohol and Drugs, 71(3), 345-350. 
Gorka, S. M., Phan, K. L., \& Childs, E. (2018). Acute calming effects of alcohol are associated with disruption of the salience network. Addiction Biology, 23(3), 921-930.

Guerri, C., \& Pascual, M. (2010). Mechanisms involved in the neurotoxic, cognitive, and neurobehavioral effects of alcohol consumption during adolescence. Alcohol, 44(1), 15-26.

Gundersen, H., Specht, K., Grüner, R., Ersland, R., \& Hugdahl, K. (2008). Separating the effects of alcohol and expectancy on brain activation: An fMRI working memory study. Neuroimage, 42(4), 1587-1596.

Harrell, P. T., \& Juliano, L. M. (2009). Caffeine expectancies influence the subjective and behavioral effects of caffeine. Psychopharmacology, 207, 335.

Hrobjartsson, A., \& Gøtzsche, P. C. (2004). Is the placebo powerless? Update of a systematic review with 52 new randomized trials comparing placebo with no treatment. Journal of Internal Medicine, 256, 91-100.

Kirkpatrick, M. G., \& Wit, H. (2013). In the company of others: Social factors alter acute alcohol effects. Psychopharmacology, 230(2), 215-226.

Knibb, G., Roberts, C. A., Robinson, E., Rose, A., \& Christiansen, P. (2018). The effect of beliefs about alcohol's acute effects on alcohol priming and alcohol-induced impairments of inhibitory control. PLoS One, 13(7), e0201042.

Lachenmeier, D. W., Pflaum, T., Nieborowsky, A., Mayer, S., \& Rehm, J. (2016). Alcohol-free spirits as novel alcohol placebo - A viable approach to reduce alcohol-related harms? International Journal of Drug Policy, 32(2016), 1-2.

Marlatt, G. A., \& Rosenhow, D. J. (1980). Cognitive processes in alcohol use: Expectancy and the balanced placebo design. In Mello, N.K. (ed.) advances in substance abuse. Behavioral and Biological Research, 80(1), 159-199.

Marlatt, G. A., \& Rosenhow, D. J. (1981). The balanced placebo design: Methodological considerations. Addictive Behaviors, 6(2), 107-122.

Mendelson, J. H., McGuire, M., \& Mello, N. K (1984). A new device for administering placebo alcohol. Alcohol, $1(5), 417-419$.

Moonat, S., Starkman, B. G., Sakharkar, A., \& Pandey, S. C. (2010). Neuroscience of alcoholism: Molecular and cellular mechanisms. Cellular and Molecular Life Sciences, 67(1), 73-88.

Morean, M. E., \& Corbin, W. R. (2010). Subjective response to alcohol: A critical review of the literature. Alcoholism, Clinical and Experimental Research, 34(3), 385-395.

Nagy, K., Cziboly, Á., \& Bárdos, G. (2007). Placebo and the effect of alcohol: To know or not to know? Clinical Neuroscience, 60(S1), 77.

Price, D.D., Finniss, D.G. \& Benedetti, F.A (2008). Comprehensive review of the placebo effect: Recent advances and current thought. Annual Review of Psychology, 59, 565-568.

Rodríguez Rodríguez, T. S., Castro García, P., Manzo Ríos, M. I., \& Mora Lee, S. (2016). Comparison of Neurocognition and behavior in alcohol with placebo group. International Multispecialty Journal of Health (IMJH), 2, 13-20.

Ross, M., \& Olson, J. M. (1981). An expectancy-attribution model of the effects of placebos. Psychological Review, 88, 408-437.

Schlauch, R. C., Waesche, M. C., Riccardi, C. J., Donohue, K. F., Blagg, C. O., Christensen, R. L., \& Lang, A. R. (2010). A meta-analysis of the effectiveness of placebo manipulations in alcohol-challenge studies. Psychology of Addictive Behaviors, 24(2), 239-253.

Shapiro, A. K., \& Shapiro, E. (1997). The powerful placebo. From ancient priest to modern psychican. Baltimore: Johns Hopkins University Press.

Stevens, S., Cludius, B., Bantin, T., \& Gerlach, A. L. (2014). Influence of alcohol on social anxiety: An investigation of attentional, physiological and behavioral effects. Biological Psychology, 96, 126-133.

Szabo, A., Szemerszky, R., Dömötör, Z., Gresits, I., \& Köteles, F. (2017). Laboratory investigation of specific and placebo effects of a magnetic bracelet on a short bout of aerobic exercise. Journal of Sport Behavior, 40(4), 410-422.

Szemerszky, R., Dömötör, Z., \& Köteles, F. (2013). What is inside a cup of coffee: Caffeine or expectations? Psychology and Health, 28(Suppl.1), 317.

Thompson, W. G. (2000). Placebos: A review of the placebo response. The American Journal of Gastroenterology, 95(7), 1637-1643.

Vuchinich, R. E., Tucker, J. A., \& Sobell, M. B. (1979). Alcohol, expectancy, cognitive labeling, and mirth. Journal of Abnormal Psychology, 88(6), 641-651.

Weafer, J., Gallo, D. A., \& De Wit, H. (2016). Acute effects of alcohol on encoding and consolidation of memory for emotional stimuli. Journal of Studies on Alcohol and Drugs, 77, 86-94.

Zahr, N. M., Kaufman, K. L., \& Harper, C. G. (2011). Clinical and pathological features of alcohol-related brain damage. Nature Reviews: Neurology, 7(5), 284-294.

Publisher's Note Springer Nature remains neutral with regard to jurisdictional claims in published maps and institutional affiliations. 